\title{
A Method for Comparing Scholarly Journals as Service Providers to Authors
}

\author{
Bo-Christer Björk \\ Hanken School of Economics \\ P.O. Box 479 \\ FIN-00101 Helsinki \\ Bo-Christer.Bjork@hanken.fi \\ Anssi Öörni \\ Helsinki School of Economics \\ P.O. Box 1210 \\ FIN-00101 Helsinki \\ Finland \\ oorni@hse.fi
}

This is a so-called personal version (author's manuscript as accepted for publishing after the review process but prior to final layout and copyediting) of the article

Björk, Bo-Christer, Öörni, Anssi, 2009, A Method for Comparing Scholarly Journals as Service Providers to Authors,

Serials Review, Vol. 35. No. 2, June 2009, pp. 62-69

Readers are kindly asked to use the official publication in references. 


\title{
A Method for Comparing Scholarly Journals as Service Providers to Authors
}

\author{
Bo-Christer Björk and Anssi Öörni
}

\begin{abstract}
When authors of scholarly articles decide where to submit their manuscripts for peer review and eventual publication, they often base their choice of journals on very incomplete information abouthow well the journals serve the authors' purposes of informing about their research and advancing their academic careers. The purpose of this study was to develop and test a new method for benchmarking scientific journals, providing more information to prospective authors. The method estimates a number of journal parameters, including readership, scientific prestige, time from submission to publication, acceptance rate and service provided by the journal during the review and publication process. Data directly obtainable from the web, data that can be calculated from such data, data obtained from publishers and editors, and data obtained using surveys with authors are used in the method, which has been tested on three different sets of journals, each from a different discipline. We found a number of problems with the different data acquisition methods, which limit the extent to which the method can be used. Publishers and editors are reluctant to disclose important information they have at hand (i.e. journal circulation, web downloads, acceptance rate). The calculation of some important parameters (for instance average time from submission to publication, regional spread of authorship) can be done but requires quite a lot of work. It can be difficult to get reasonable response rates to surveys with authors. All in all we believe that the method we propose, taking a "service to authors" perspective as a basis for benchmarking scientific journals, is useful and can provide information that is valuable to prospective authors in selected scientific disciplines.
\end{abstract}

\section{Introduction}

Authors of scientific papers deciding where to submit for publication have to make difficult choices based on rather incomplete information. Important parameters of journal performance, such as the number of subscribers and readers, the acceptance rate of submitted manuscripts, the lead time from initial submission to publication of accepted papers are usually not available. In several research communities studies have been made which rank journals according to their perceived scientific quality and prestige. A more objective measure for scientific quality can be reached by using the impact factors calculated by the Institute of Scientific Information using their citation database. We have earlier proposed a method for benchmarking scientific journals from the submitting author's viewpoint, which takes into account a much wider range of parameters. ${ }^{1}$ This paper recapitulates the method and reports on our testing of the method on three different sets of journals in the fields of construction IT, construction management and information systems. Particular attention is given to the conclusions we draw about its applicability.

Benchmarking as a method has been widely used in industry, for instance, when particular firms want to compare their procedures with competitors and perhaps with firms from other branches of industry. ${ }^{2}$ The results of benchmarking are usually not singular numerical values. Rather, the output comprises graphs showing the position of the firm relative to the metrics.

The starting point for the method is the view of a journal as a service provider to authors rather than to readers alone. The fact that authors usually give away the fruit of their labor for free to publishers and that they are willing to pay publication charges in the order of 1500-3000 USD for publication in certain Open Access journals is a clear indication of the fact that publication is very valuable service for them. 


\section{Previous research}

Other researchers have previously studied the features that authors value in peer- reviewed journals. For instance Rowlands et al. surveyed the opinions of nearly 4,000 senior academics. ${ }^{3}$ They found that authors in particular appreciate the ability to reach a very specific group of key readers, their research community, and they want the recognition publishing in peer-reviewed scientific journals offers. Gibler and Ziobrowski made a survey of US academic authors who had published in three journals, identifying four factors: (1) fair and efficient editorial process, (2) probability of publication, (3) quality, and (4) ranking for promotion and tenure. ${ }^{4}$ Swan and Brown have conducted a number of studies concerning what motivates authors. ${ }^{5}$ Summarizing their research the two most important factors seem to be readership and the quality of the journal. They also found that authors base their estimates of readership more on hearsay that fact.

Björk and Turk surveyed 236 authors in construction IT concerning their reading and publishing preferences. ${ }^{6}$ When deciding where to submit an article the reasons in decreasing order of importance were (on a Likert scale of 1-5):

- The journal has relevant readership (4.2)

- High academic status (4.2)

- Has a large circulation (3.2)

- Short lead time from submission to publication (3.1)

- It is on a shortlist of approved journals (promotion, funding) (2.9)

- Journal is indexed in established bibliographic databases (2.9)

- Likely to be accepted (not too tight review process) (2.5)

- Journal articles are available for free on the web (2.4)

- Journal is indexed in a free database (2.4)

Since the above studies were made the scientific publishing system has undergone huge changes and recent experiences indicate that the importance of being indexed by the ISI has increased (in particular in Asian countries), and that well functioning web submission and manuscript tracking systems matter to authors. Electronic availability of the journal is almost assumed, at least in the STM (Science, Technology, and Medicine) fields. In the case of Open Access journals a possible author charge, usually between 1500 and 3000 USD, is an important parameter that hinders many potential contributors.

\section{The net value of submission model}

Each academic journal has multiple interest groups it seeks to serve. In addition to the publisher, it is possible to distinguish at least three interest groups, which, though somewhat overlapping, often have somewhat conflicting needs and wants: authors, academic readership, and readership among practitioners. As the wants of the interest groups are often mutually conflicting and in conflict with those of the publisher, they cannot be fully satisfied simultaneously and the journals will have to make strategic choices. These choices are reflected in the quality of the journal's processes and the services it offers. As a result, the value of the services offered to its different stakeholder groups may fluctuate. This fluctuation leads to performance information becoming obsolete and necessitates the members of the interest groups to update their information at times of decision, e.g. when choosing the submission venue for a manuscript. To facilitate this updating of information, we have constructed a net value submission model, which integrates the performance characteristics of journals into a coherent frame. The model is built from the submitting author's point of view and seeks to serve as the base for benchmarking the prospective submission venues for a manuscript. Thus, the premise of this model is that the journal is a service provider to the submitting author. 
The term net value of submission can be used as a short form for the risk- and cost adjusted expected value of submitting a paper to a particular journal. Risk adjustments in the form of premiums are standard practice in many walks of life. When uncertainty over the course of future events prevails, people often take into account the various contingencies when contemplating their actions. In the academic publishing context authors often have to choose between submitting a manuscript to a prestigious journal (e.g. impact factor 2.0) with a high (e.g. 90\%) rejection rate or to a lesser journal (e.g. impact factor 0.9 ) with a lower (e.g. 50\%) rejection rate. The much simplified expected value of submitting to the more prestigious journal can be calculated as a weighted average of the two possible outcomes, i.e. acceptance and rejection. Using the above figures the expected net value is $0.2(0.1 * 2.0+0.9 * 0=0.2)$. For the less prestigious journal the calculation yields an expected outcome of 0.45 . On the surface the author should thus choose the less prestigious outlet. In practice each individual has a different preference set. Some are more risk averse than others. For some it might be absolutely imperative to get an article in a top journal in order to get tenure. Typically these calculations are informal as no formal frame for such consideration exists. The submission net value model is designed to fill this void for the academic authors, by helping to provide explicit background information as a basis for decision making, just like consumers buying a car can get a lot of info to help them in the decision making.

In figure 1 the 30 different concepts included in the model are illustrated, grouped into four different blocks: Infrastructure, Readership, Prestige and Performance.

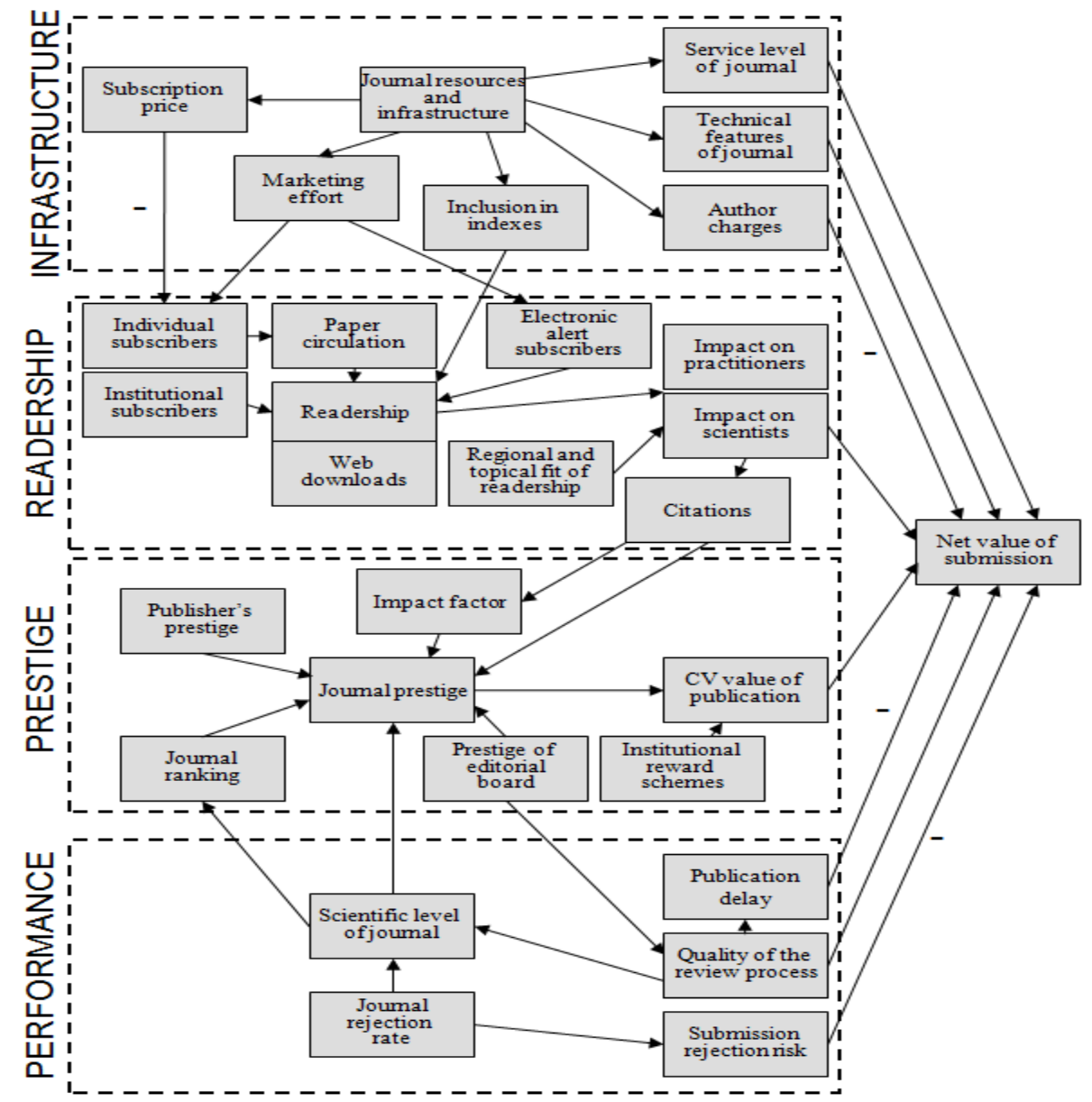

Figure 1. A graphical illustration of different factors influencing an author's choice of where to submit a manuscript for publication 1 
The model has been constructed around eight factors identified as potential direct influences on the author's choice of submission venue for a manuscript. The identified factors are as follows:

- CV value of publication

- Impact on scientists and practitioners

- Quality of the review process

- Publication delay

- Submission rejection risk

- Service level of journal

- Technical features of the journal

- Author charges

We posit that these factors are in the core of deliberation over the submission venue choice, yet, their relative impact on any single decision may vary. Their impact is contingent to factors not directly related to the content or quality of the manuscript, e.g. to the stage of the author's career and to the mechanics of the employer's reward system. As the relative impact of the factors may vary, we don't seek to calculate universal net value figures for any one journal. Rather, the aim of the model is to identify the salient factors of the submission decision, and to provide factual data for the authors to base their submission decision on.

The eight salient factors are products of a larger set of interrelated background factors, many of which are invisible to a casual author. These background factors are pictured in the model to provide better understanding of the content of the more visible salient factors. While the relationships between the background factors and the salient factors are often difficult to measure, causalities are in most cases clear. We will next discuss these influences of the background factors on the salient factors. The discussion will follow the categories of the model depicted in Picture 1.

\section{Infrastructure}

Journal infrastructure refers to resources, both technical and non-technical, made available to the journal by the publisher. The determining factor in the infrastructure block is the resources available to the journal. These resources include editorial staff, marketing resources, information technology infrastructure, and so forth. The technical resources influence the level of technical services, such as electronic submission and review tracking systems, color for figures, electronic journals hypertext features, and availability of digital pre-prints. The non-technical, organizational resources largely determine the marketing efforts of the journal, and the level of services available to the authors: timeliness of the review process, prompt replies to queries, handling of proofs, off, etc. Finally, funding of the journal sets the viable subscription price and possible author charges. While charges for extra pages, color reproduction, etc. have been used for decades, comprehensive author charges as the main source of revenue is a relatively new concept, related particularly to open access journals. Assuming all other criteria equal, the author has to balance the author charges with the wider readership that the open access journal might offer.

\section{Readership}

Readership of an academic journal comprises both academic readers and practitioners. The readership block deals with the readership of an average article published in the journal. Prestige and subscription price have largely been the determinants of the readership of conventional journals. These have influenced both individual and institutional subscriptions which combine to determine the circulation of the journal. However, the relationship between subscriptions and readership is becoming increasingly complex for conventional subscriptions are becoming less important compared to electronic licenses and to bundling of the journals of a publisher into "big deal" licenses. At the extreme of open access journals, subscriptions have become irrelevant as anyone with access to the Internet can read the articles. For open access journals the most 
interesting statistics are web downloads of full articles, and the number of individuals who have signed up for table of contents alerts.

The size of the readership, the number of average readers per article, is not the only factor authors enter into the equation when determining the venue for submitting their manuscripts. Regional distribution of potential readers and their areas of interest (topical fit) are important considerations since authors typically want to target a specific audience, readers who share the interest in the research topic. Targeting the right readership benefits the author most through citations to his work. The author may be better off submitting to a highly specialized journal with a relatively small yet highly focused readership than targeting a bigger journal with more general content. The former alternative promises to get the experts in the research community to read the article. (Originally scholarly journals developed as parts of scientific societies, with all members receiving copies.)

Impact on academics and practitioners denotes the effects the article can be expected to have on readers' thinking. The expected impact is determined by the total number and relevance of the readership (specialists in the same field, colleagues in the researcher's network, industry experts in his own country etc.).

\section{Prestige}

Prestige of the journal is a central consideration for the submitting author as articles published in high prestige journals carry both short and long term benefits in terms of performance related bonuses and career advancement. These perceived benefits are gathered together in the $\mathrm{CV}$ value of publication construct in the prestige block of the net value of submission model ${ }^{1}$. The CV value denotes the incremental value that researchers gain on publishing in the journal. It operates on many levels, e.g. on institutional, national, and research community level, and the value materializes through helping the researcher to obtain positions, tenure, research grants etc.

The prestige block further depicts the factors that determine the $\mathrm{CV}$ value of publication. The central determinant is the prestige of the journal. While journal prestige as such often cannot be assessed, there are several indicators exist can be used to approximate it. The journal impact factor, journal rankings, prestige of the editorial staff, and, finally, prestige of the publisher all embrace an aspect of journal prestige. In order to identify the short term influence of journal prestige one only needs to review the reward policies of the employing institution, research funding agencies, national governments etc., which usually employ one or more of the aforementioned overt indicators of prestige as the yard sticks of author performance.

Prestige of the publisher operates largely through major commercial and academic publishers and bigger scientific societies having become brand names in their own right. Publisher's brand is one vehicle of prestige, even if quality of journals for most publishers varies. The editorial board is another mean of communicating prestige, and its importance is especially high for new journals to start attracting submissions. The impact factor is a market-driven measure of prestige: impact factors are determined by the average number of citations to the published articles. Thomson Scientific publishes the impact factors that are most often used. It should be noted, however, that the term citation as used in the net value of submissions model is more comprehensive than what is used in association with the impact factors of the Scientific Unit of the Thomson Reuters. There are efforts in motion to develop measures of citations, using the bulk of material on the web as a basis. Journal rankings are measures of prestige based on many factors and often developed through polls with researchers in a given field of interest.

\footnotetext{
${ }^{1} \mathrm{CV}$ is the abbreviation for curriculum vitae
} 


\section{Performance}

The last block of the net value of submission model deals with the journal performance. Journal performance captures aspects in the publishing process that are not directly under the submitting author's control. The model identifies three perceptible indicators for journal performance: 1) quality of the review process, 2) publication delay, and 3) the rejection rate. Of these the rejection rate and the publication delay are rather stable yet they are often difficult to assess for few journals publish the actual figures. The quality of the review process, on the other hand, is prone to variation as it is highly dependent on the individual input of the reviewers. Alas, this also makes it relatively difficult to assess the probability of a high quality review process.

Considerable differences from journal to journal on account of all three indicators of journal performance exist. Review processes range from quick review done in a matter of hours to interaction processes between reviewers and authors lasting several months, sometimes even resembling supervision of a dissertation. A lengthy review process offers the author the opportunity to improve on the manuscript. The down side is that it also adds to the publication delay.

The overall rejection rate of a journal is one of the most important factors to contemplate when deciding on the venue of submitting a manuscript. The rejection risk, of course, is not a constant. It is tightly related to the fit between the manuscript and the journal's focus. The better the fit the lower the expected rejection rate is. Good fit also increases the chances of getting competent reviewers for the manuscript, which is reflected in consistent reviews and lesser risk of rejection for unforeseen causes. This is also one of the reasons for the popularity of submitting to special issues.

Average publication delay and submission rejection risk are among the major cost factors in the overall decision tree. The publication delay is typically the sum of a number of factors including the quality of the review process and the waiting time in the publishing queue. Considerable variation in publication delays exist between different disciplines. A three-year delay may be acceptable in some sciences, yet, may invariably lead to findings being obsolete at the time of publication for most areas with strong dynamics, such as technological change.

\section{Measuring the different parameters in the model}

Looking at the different parameters in the model there are some that are easily available as such, and some for which raw data is available but needs to be collected and analyzed. Some of the measurable factors are, however, often not publicly available to prospective authors since many journals treat such figures as trade secrets, in particular if they could be considered bad publicity.

Examples of measurable and easily available factors include: subscription price, author charges, impact factor, inclusion in indexes, journal ranking. Examples of measurable factors, which often are not available include: number of subscribers, paper circulation, downloads, publication delay, journal rejection rate.

For some of these latter factors there could be roundabout ways to obtain them. One could for instance make surveys with authors in a research field and ask them about their readership, paper rejections etc. and get crude estimates for some factors. This would also help in measuring some of the more qualitative factors such as the service level of a journal. However, this is quite tedious and resource demanding. Also, citation analysis could be used, analysis that would go further than just the core journals that Thomson Scientific tracks.

\section{The test cases}

The method was tested on three sets of journals in different research areas. General information about the test cases is provided in table 1 below. The number of articles per year was 235 for 
Construction IT journals, 475 for Construction Management journals and 265 for Information systems journals (see Table 2 for a list of the journals included in the study). Tests 1 and 2 have been reported elsewhere to the researcher communities in question ${ }^{7,8}$, but with a focus on the results, not on how the method worked. The reporting here is concerned with testing the method itself and the results, per se, are secondary.

Table 1. Data about the test cases.

\begin{tabular}{lccccc}
\hline Subject area & Number of journals & Articles per year & Sample for author questionnaire & Answers & Response rate \\
\hline Construction IT & 8 & 235 & - & - & - \\
Construction Management & 7 & 475 & 397 & 140 & $35 \%$ \\
Information Systems & 7 & 265 & 289 & 26 & $9 \%$ \\
\hline
\end{tabular}

Table 2. Journals included in the test cases and their abbreviations.

\begin{tabular}{ll}
\hline Abbreviation & Journal Name \\
\hline AIC & Automation in Construction \\
BRI & Building Research \& Information \\
CACIE & Computer-Aided Civil and Infrastructure Engineering \\
CI & Construction Innovation \\
CME & Construction Management and Economics \\
ECAM & Engineering, Construction and Architectural Management \\
EJIS & European Journal of Information Systems \\
IBM SYST J & IBM Systems Journal \\
IJAC & International Journal of Architectural Computing \\
IJDC & International Journal of Design Computing \\
IJPM & International Journal of Project Management \\
ISR & Information Systems Research \\
ITCON & Journal of Information Technology in Construction \\
I\&M & Information \& Management \\
JCCE & Journal of Computing in Civil Engineering \\
JCEM & Journal of Construction Engineering and Management \\
JMIS & Journal of Management Information Systems \\
MISQ & Management Information Systems Quarterly \\
SJIS & Scandinavian Journal of Information Systems \\
\hline
\end{tabular}

In each of the three cases, different subsets of all the metrics in the models were measured. Table 3 contains a summary of the metrics evaluated. 
Table 3. Factors identified in the method and measured in the three test cases.

\begin{tabular}{|c|c|c|c|c|c|}
\hline Factor & Scale & $\begin{array}{c}\text { Data } \\
\text { Source }\end{array}$ & $\begin{array}{c}\text { Case } \\
1\end{array}$ & $\begin{array}{c}\text { Case } \\
2\end{array}$ & $\begin{array}{c}\text { Case } \\
3 \\
\end{array}$ \\
\hline \multicolumn{6}{|l|}{ INFRASTRUCTURE } \\
\hline Subscription price & Price/article & $\mathrm{DA}, \mathrm{CBC}$ & $*$ & & \\
\hline Inclusion in indexes & Likert scale & $\mathrm{DA}, \mathrm{AS}$ & & * & $*$ \\
\hline Service level of journal & Likert scale & AS & & $*$ & $*$ \\
\hline Technical features of journal & Likert scale & DA & & & $*$ \\
\hline \multicolumn{6}{|l|}{ READERSHIP } \\
\hline Individual subscribers & Number & FP, AS & & & \\
\hline Institutional subscribers & Number & $\mathrm{FP}, \mathrm{AS}$ & & & \\
\hline Paper circulation & Number & FP & & & \\
\hline Web downloads & Number/article & FP & $*$ & & \\
\hline Readership & $\%$ of scientists & AS & & $*$ & $*$ \\
\hline Electronic alert subscribers & Number & FP & $*$ & & \\
\hline $\begin{array}{l}\text { Regional and topical fit of } \\
\text { read. }\end{array}$ & Distribution & $\mathrm{CBC}, \mathrm{FP}$ & $*$ & & \\
\hline \multicolumn{6}{|l|}{ Impact on practitioners } \\
\hline Impact on scientists & & & & $*$ & $*$ \\
\hline Citations & Number/article & $\mathrm{CBC}$ & & * & $*$ \\
\hline \multicolumn{6}{|l|}{ PRESTIGE } \\
\hline Impact factor & Number/article & DA & $*$ & * & $*$ \\
\hline Journal ranking & Ordinal /Likert & DA & & & \\
\hline Journal prestige & & & & & * \\
\hline $\begin{array}{l}\text { Prestige of the editorial board } \\
\mathrm{CV} \text { value of publication }\end{array}$ & Likert scale & $\mathrm{CBC}$ & & $*$ & $*$ \\
\hline \multicolumn{6}{|l|}{ PERFORMANCE } \\
\hline Journal rejection rate & $\%$ & FP & & * & $*$ \\
\hline Quality of the review process & Likert scale & AS & & & $*$ \\
\hline Publication delay & Months & $\mathrm{CBC}, \mathrm{FP}$ & $*$ & & $*$ \\
\hline
\end{tabular}

\section{Test case 1, Construction IT journals}

The method was first tested on a sample of journals publishing research articles studying the use of information technology in the design and construction of buildings. ${ }^{7}$ This is a relatively new research area where the first dedicated peer-reviewed journals were launched in the early 1990s. The sample also included one open access journal. One of the most interesting results of this case was that there are big differences in the subscription prices of journals per published article (Figure 2), which indirectly also reflects the low number of subscribers to the most expensive journals. Interestingly, the journal with the highest impact factor was at the same time the cheapest. This is in line with other studies were this phenomenon has been observed., ${ }^{9,10}$ 


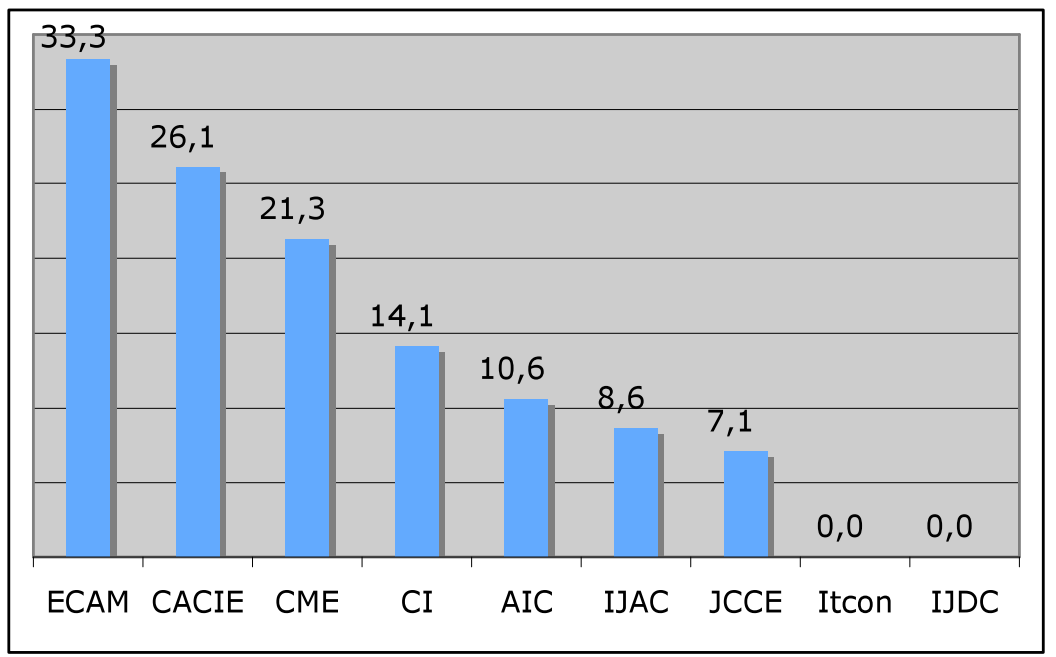

Figure 2. Estimated institutional subscription price per article of different construction IT journals in Euros. The two journals with zero prices are open access journals.

Another interesting analysis concerned the geographical spread of authorship in the studied journals. Despite the fact that all journals except one (The Journal of Computing in Civil Engineering published by the American Society for Civil Engineers) aspired to be fully international there were very clear differences in where the authors came from, as can be seen in table 4 below.

Table 4. Geographic spread of authors (\%) and total number of authors and articles per journal for construction IT journals

\begin{tabular}{lrrrrrr}
\hline \multirow{2}{*}{ Author location } & \multicolumn{7}{c}{ Journal } & \multirow{2}{*}{ In total } \\
\cline { 2 - 5 } & \multicolumn{1}{c}{ ITcon } & CI & JCCE & AIC & CACIE & \\
\hline North America & 20,2 & 13,7 & 66,7 & 21,4 & 45,8 & $37,5 \%$ \\
South America & 0 & 0 & 0,2 & 0 & 0 & $0,1 \%$ \\
Africa & 1 & 0 & 0,7 & 0 & 0 & $0,3 \%$ \\
Great Britain & 25,3 & 24 & 4,5 & 14,7 & 3 & $12,1 \%$ \\
Central Europe & 15,8 & 5,1 & 4 & 7,5 & 8,7 & $8,1 \%$ \\
Northern Europe & 21,5 & 1,1 & 0 & 0,3 & 1,5 & $4,2 \%$ \\
South \& East Europe & 6,4 & 1,7 & 1,4 & 2 & 7,2 & $3,8 \%$ \\
Asia & 8,4 & 33,2 & 20,9 & 48,9 & 32,1 & $29,5 \%$ \\
Australia \& Oceania & 1,4 & 21,2 & 1,6 & 5,2 & 1,7 & $4,5 \%$ \\
\hline
\end{tabular}

\section{Test case 2, Construction Management journals}

The second test case concerned journals dedicated to research concerning construction management and economics ${ }^{8,11}$. The research community in this area is bigger than in construction IT and the leading journals have a slightly longer history, publish more articles per year and have a wider circulation than construction IT journals. This case included a web survey with authors of papers published in any of the studied journals, which made it possible to measure the degree of satisfaction with the service level of the journals as well as the helpfulness of the review process. 
Table 5. Assessments of publisher service level and the helpfulness of the review process of the construction management journals. The figures show the percentage of authors who rated a journal they were familiar with high (4) or very high (5) on a five-graded Likert scale

\begin{tabular}{lrrrrrrr}
\hline & AIC & BRI & CI & CME & ECAM & IJPM & JCEM \\
\hline Publisher service level & 52 & 60 & 38 & 79 & 42 & 61 & 57 \\
Helpfulness of review process & 57 & 57 & 35 & 77 & 48 & 57 & 74 \\
\hline
\end{tabular}

\section{Test case 3, Information Systems journals}

The third test case concerned journals in Information Systems, a discipline concerned with how companies and organizations implement ICT solutions to achieve better productivity and customer value. This test case has not been previously reported and thus the reporting of the results is more comprehensive in this article.

We gathered data through a survey from active authors in the IS field. We decided to have the sample frame of corresponding authors who had published during the three most recent years in the journals included in the study. A web-based questionnaire was developed by using the Webropol tool. The selection of the journals included in the study was based on their prestige and representativeness of the IS field. To draw the sample, we went through three recent volumes (2005-2007) for the seven IS journals included in the study to extract contact information for the corresponding authors of each article published. After removing out duplicates and non-working email addresses, we ended up with 289 unique e-mail addresses. The authors were contacted by sending an e-mail invitation to participate in the survey. We first contacted the subjects in December 2007 and again in January 2008. After these two rounds of contacts we received a total of 26 completed answers, which left us with the response rate of $9 \%$. For the number of observations we managed to accumulate, as well as the response rate, are rather low, we deemed it prudent to apply the basic statistics rather than statistical tests as the means of analysis. Author charges were excluded from the analyses since none of the journals charge for accepted manuscripts to be printed.

The questions were asked using two different scales. For some factors the authors were asked to put the seven journals into a ranking order, with the highest rated journals assigned the rank 1 and the lowest rated the rank 7. For other factors they were asked to rate the journals on a Likert scale of 1 to 5 , with 5 representing the highest value for that parameter (for instance service level of the journal) and 1 representing the lowest. Table 6 shows the results concerning those questions which used a ranking. The rankings of the journals, as submission and publication venue and as a source of research ideas, help us reason about the influence of the individual constructs of the submission net value model. We benchmarked the journals involved in the questionnaire by asking the respondents to rank the journals in order of preference as 1) a submission venue, 2) publication venue, and 3) source for research ideas.

Table 6. Journals in order of preference (mean rankings) as submission and publication venues as well as sources of research ideas. The lower the figure the higher the ranking of the journal. For each factor the highest ranked journal is indicated with bold. We have also as background information included the Journal Impact Factors from ISI.

\begin{tabular}{|c|c|c|c|c|c|c|c|}
\hline \multirow[t]{2}{*}{ Journal as a } & \multicolumn{7}{|c|}{ Journal } \\
\hline & SJIS & EJIS & $\mathrm{I} \& \mathrm{M}$ & MISQ & JMIS & ISR & $\begin{array}{c}\text { IBM } \\
\text { SYST J }\end{array}$ \\
\hline submission venue, & 4.37 & 4.71 & 4.87 & 3.10 & 2.71 & 4.10 & 4.00 \\
\hline publication venue, & 4.56 & 4.44 & 4.88 & 3.18 & 2.59 & 4.24 & 3.87 \\
\hline source for research ideas. & 4.61 & 3.87 & 4.27 & 3.55 & 3.67 & 4.32 & 3.91 \\
\hline Journal impact factor & $\mathrm{n} / \mathrm{a}$ & 0.712 & 1.631 & 5.826 & 1.867 & 2.682 & 1.214 \\
\hline
\end{tabular}


For most of the journals authors rank them on a very similar level for each of the three facets. It seems, nevertheless, that the respondents are more eager to read the European Journal for Information Systems than to submit to it. The reverse is true for the Journal of Management Information Systems.

Our data suggest that authors do not focus on the prestige of the paper alone when selecting a journal for submission or publication (the lower the rank the higher the preference). Journal of Management Information Systems clearly beat Management Information Systems Quarterly both as a submission and publication venue. The most desirable publication venues diverted rather clearly from the rest of the journals. The relatively high means for ratings indicate that heterogeneity of the information systems field affects preferences for the journals. The varied foci of the journals and topics of the individual research manuscripts are matched, and this matching strongly influences the selection of the submission venue even though prestige of the journal exerts certain amount of influence in the process.

The results for the questions using a Likert scale are shown in the following table (table 7).

Table 7. Estimated (mean) values for submission criteria. Likert scale of 1 to 5 with 5 being the highest. The top scoring journals for each question is shown with bold. Note that high scores for the factors publication delay and submission rejection risk are actually negative for submitting authors.

\begin{tabular}{lcccccccc}
\hline \multirow{2}{*}{ Attribute } & \multicolumn{10}{c}{ Journal } \\
\cline { 2 - 8 } & SJIS & EJIS & I\&M & MISQ & JMIS & ISR & IBM \\
& 1.74 & 3.38 & 3.32 & $\mathbf{4 . 9 6}$ & 4.68 & 4.88 & 2.13 \\
\hline CV value & 1.94 & 2.30 & 2.57 & 2.58 & 2.38 & 2.38 & $\mathbf{3 . 4 8}$ \\
size of readership among practitioners & 2.00 & 3.54 & 3.56 & $\mathbf{4 . 8 4}$ & 4.40 & 4.76 & 2.00 \\
size of readership among academics & 3.33 & 4.07 & 3.10 & $\mathbf{4 . 6 7}$ & 4.18 & 4.59 & 2.30 \\
quality of the review process & 3.38 & 3.25 & 3.56 & 3.78 & 3.65 & $\mathbf{3 . 8 4}$ & 2.56 \\
publication delay & 1.67 & 3.05 & 2.74 & $\mathbf{4 . 5 2}$ & 4.05 & 4.35 & 1,79 \\
submission rejection risk & 2.71 & 3.73 & 3.07 & $\mathbf{4 . 2 8}$ & 4.11 & 4.05 & 2.57 \\
service level of the journals & 2.17 & 3.80 & 3.57 & 3.78 & 3.57 & $\mathbf{3 . 8 3}$ & 2.00 \\
quality of technical features & & & & & &
\end{tabular}

The value of the publication for the author is the target of a few public measures of which the impact factor is, perhaps, the one most often cited. Therefore, it is interesting to compare the impact factors with the CV value evaluations attached to the journals, as the impression the authors have about the benefits of publishing, is what counts in their submission decisions. All of the journals, except for the Scandinavian Journal of Information Systems (ISI accreditation pending), are indexed in the Thomson Science Citation Index with impact factors ranging from 0.712 to 5.826.

The objective rankings, based on the ISI citation index impact factors, can be compared to the CV value of publishing in the. The most prestigious triplet of the journals was ranked according to their impact factors, and the same applies to the Scandinavian Journal of Information Systems, which received the lowest score. For the other journals, however, the CV values did not rank in the order of their impact factors. It should also be noted that, the top three journals received $\mathrm{CV}$ value evaluations that were substantially closer to one another than their impact factors might have suggested.

In general, the $\mathrm{CV}$ value appraisals were more level than the impact factors. Information \& Management (I\&M) and European Journal of Information Systems (EJIS), for example, were evaluated almost equal while $I \& M$ has an impact factor twice that of EJIS'. Further, Scandinavian Journal of Information Systems did not lag far behind the IBM Systems Journal, even though SJIS 
lacked the ISI citation index impact factor at the time of the survey. It appears that from the perspective of the CV value an impact factor is a bloated indicator of the journal's influence.

The impact of a journal on its readership captures the size of readership among both academics and practitioners. The focus of the journals in the study varies as some journals have an expressed practical focus (e.g. MISQ and IBM SYST J) while others lean more towards the academic audience (e.g. ISR). An objective measure for the size of the readership, while not always able to distinguish between the two subpopulations, would be the number of downloads per paper for the journal. This measure, however, is mostly unavailable for the authors to base their decisions on. Therefore, they have to use secondary information to construct their mental impression of the impact of the journal.

Our data suggest that authors hold the academic impact of the journals in general much higher than the practical impact. The exceptions to this rule are the Scandinavian Journal of Information Systems, which received equal evaluations for its impacts and the IBM Systems Journal, which was seen as having more influence on practitioners than on academics.

Average publication delay and submission rejection risk are two factors for which quite objective measures can be calculated given the basic data is available. In the best of cases journals publish the figures. Sometimes publication delays can be calculated if data on submission times etc. is published with the articles. It is rarer to get precise data on the number of submission and rejections, but journals often inform about the general level. In this case we studied these figures by asking the authors to rate the journals.

Our data also suggest that the length of the perception of the publication delay is somewhat associated with the journal impact factor, even though this association is not altogether consistent. In general, however, the higher the impact factor the longer is the estimated publication delay. IBM Systems Journal was deemed to have the shortest publication delay while Information Systems Research was estimated to have the longest publication delay.

Submission rejection risk is one of the cost factors that authors have to consider when choosing the submission venue. It should be related to the prestige of the journal if prestige is the predominant determinant of author decisions. The high prestige journals attract more submissions which should increase the rejection rate. Our data suggest that submission rejection risk is highly associated with journal's impact factor. In fact, the estimated submission rejection risk seems to follow the impact factor more closely than most other factors of the author submission net value model.

The benchmarking of the Information Systems Journals also included questions about the quality of the review process, the service level of the journal (timeliness of review, prompt reply to queries, handling of proofs, receiving of off prints, etc.) and the technical features (electronic submission system, color for figures and hypermedia features for electronic journals, etc.) of the journal, rating the journals on a Likert scale of 1 to 5 . There were marked differences in the perceptions of the quality of the review process, where the journal with the highest score got 4.67 (MISQ with an impact factor of over 5) and the lowest 2.3. The spread of ratings was less pronounced for the service level and the technical level. The data suggest that the estimated service level of journal is associated with the impact factor of the journal. Our data suggest that the quality of the technical features is quite unrelated to the general quality of the journal (e.g. the impact factor).

\section{Conclusions}

One of the lessons learned from the test cases was that while prestige of the journal, i.e. the impact factor, is an important consideration for the author it is not likely to be the only one. Further, not all information relevant to the submission decision is publicly available. Some journals post submission and acceptance dates for papers, whereas others do not. Some editors are willing to share data, others are not. The best way to tackle this is to also include data from journals in related 
fields which are likely to be familiar to the readers and also to include more general average values if such are available (journal prices, publication delay, rejection rates). Our data suggest that authors retrieve secondary information to fill the void, which is exemplified by some reported estimates that are not congruent with the openly available information, most importantly the prestige of the journal.

Our experiences so far could be structured in two different ways, by the method of obtaining the data and by the type of measured parameter. Here we choose to discuss them according to the method of obtaining the data.

Directly available information. Some information is directly available and should naturally be included in the benchmarking due to the relative easiness of obtaining it. The most visible example is the impact factor calculated yearly by the Institute of Scientific Information. The problem with this particular parameter is however that usually not all journals to be compared are indexed by the ISI. This is particularly problematic for new journals and open access journals.In addition to the ISI statistics, numerous subjective rankings of the scientific level or prestige of journals in given scientific disciplines have been published, usually based on surveys with academics (for a good example, see Saunders. ${ }^{12}$ ). Another category of information which for a minority of journals can be found openly on the web is information about average acceptance rates and times from submission to publication.

Data from publishers. The experiences of the first author over the past decade suggest that it is very difficult to obtain data from either publishers or editors about acceptance rates, number of subscribers, web load statistics, mean time from submission to publication etc. This information is not always disclosed to even members of the editorial board of the journal. The reason for this is probably that publishers fear the bad publicity that disclosure of the true figures might lead to and prefer to keep potential authors in the dark.

Data that can be calculated from openly available information. Many journals publish information about the submission and acceptance times of published articles, usually included in the published PDFs. Firstly this makes collecting this data very labor-intensive. Secondly, the data about the actual publication time should be added to get the total elapsed time. Unfortunately such information is not systematically available so that only some of the journals in a benchmarking study can be covered.

The analysis of comparing prices per article is interesting but is as a method quickly becoming obsolete. This is due to the fact that the bulk of selling articles is moving from individual subscriptions of paper or electronic subscriptions to so-called big deals where universities obtain licenses to all the journals of a publisher, thus making it virtually impossible to track the price per journal. For such a situation totally new metrics need to be developed, for instance looking at the price per downloaded article.

Data obtained via surveys with authors. This is clearly a very important way of getting information. There are essentially two ways in which to obtain an email list of respondents to a web survey. The first one is to use existing lists of persons who have registered to get table-of-contents emails of journals, members of professional associations and networks. This method was used in a survey of general level author preferences in 2000 by the first author, but was not tried in the tree cases studied. This method seems to lead to a good response rate.

The second way is to construct an email list of all authors or corresponding authors who specifically have published in certain journals. This was used in two of the three case studies, with very different response rates $(35 \%, 9 \%)$. Our experience indicates that it makes a big difference who signs the email asking to fill in a questionnaire. The higher the prestige in the research community 
of the survey originators (preferably journal editors, society chairpersons) the higher the response rates are likely to be.

Overall the method provided results which should be of interest to authors in the three studied disciplines when considering where to submit their papers. The results complement the information which authors usually have access to, including impact factors (of journals which are in the ISI citation databases), rankings and shortlists of journals, and anecdotal personal experiences of colleagues who have submitted papers to different journals.

\section{Notes}

${ }^{1}$ B.-C. Björk, Z. Turk and J. Holmström, "Benchmarking scientific journals from the submitting author's viewpoint," Learned Publishing 19 no. 2 (2006): 147-155.

${ }^{2}$ C. E. Bogan, and M. J. English, Benchmarking for best practices: winning through innovative adaptation (New York: McGraw Hill 1994).

${ }^{3}$ I. Rowlands, D. Nicholas and P. Huntington, Scholarly communication in the digital environment: what do authors want? Findings of an international survey of author opinion. (CIBER, University College London, UK 2004) http://www.ucl.ac.uk/ciber/ciber-pa-report.pdf (accessed November 19, 2008).

${ }^{4}$ K. M. Gibler and A. J. Ziobrowski, “Authors' perceptions and preferences among real estate journals". Real Estate Economics 30 no 1 (2002): 137-57.

${ }^{5}$ A. Swan and S. Brown, "What Authors Want - The ALPSP research study on the motivations and concerns of contributors to learned journals", Learned Publishing 12 no 3 (1999): 170-172(3); A. Swan and S. Brown, Report of the JISC/OSI journal authors survey (JISC, London, 2004) http://www.jisc.ac.uk/uploaded_documents/JISCOAreport1.pdf (accessed November 19, 2008).

${ }^{6}$ B.-C. Björk, and Z. Turk, "How Scientists Retrieve Publications: An Empirical Study of How the Internet Is Overtaking Paper Media", Journal of Electronic Publishing 6 no 2 (2000) http://dx.doi.org/10.3998/3336451.0006.202 (accessed November 19, 2008).

${ }^{7}$ B.-C. Björk, Z. Turk and J. Holmström, "ITcon - A longitudinal case study of an open access scholarly journal" Electronic Journal of Information Technology in Construction 10 (2005): 349-371, http://www.itcon.org/ (accessed November 19, 2008);

${ }^{8}$ J. Bröchner and B.-C. Björk, "Where to submit? Journal choice by construction management authors" Construction Management and Economics 26 no 7(2008): 739-749.

9 C. T. Bergstrom, and T. C. Bergstrom, The economics of scholarly journal publishing (2001), http://octavia.zoology.washington.edu/publishing/ (accessed November 19, 2008);

${ }^{10}$ European Commission, Study on the economic and technical evolution of the scientific publication markets in Europe (Brussels: European Commission. Directorate General for Research 2006) http://ec.europa.eu/research/sciencesociety/pdf/scientific-publication-study_en.pdf (accessed November 19, 2008).

${ }^{11}$ B.-C. Björk and J. Bröchner, (2007) "The Value of Construction Management Journals to Submitting Authors", In: Construction Management and Economics $25^{\text {th }}$ Anniversary Conference, University of Reading, Reading, UK, 1618.7.2007, 8 p. http://www.oacs.sh.fi/publications/Bjork-\&-Brochner.pdf (accessed November 19, 2008);

${ }^{12}$ C. Saunders, Journal rankings page, web resource, Association for Information Systems (AIS) web site (2008), http://ais.affiniscape.com/displaycommon.cfm?an=1\&subarticlenbr=432 (accessed November 19, 2008). 